\title{
Sapap3 Deletion Causes mGluR5-Dependent Silencing of AMPAR Synapses
}

\author{
Yehong Wan, ${ }^{1}$ Guoping Feng, ${ }^{2}$ and Nicole Calakos ${ }^{1,2}$ \\ ${ }^{1}$ Center for Translational Neuroscience, Division of Neurology, and ${ }^{2}$ Department of Neurobiology, Duke University, Durham, North Carolina 27710
}

Synaptic transmission mediated by AMPA-type glutamate receptors (AMPARs) is regulated by scaffold proteins in the postsynaptic density. SAP90/PSD-95-associated protein 3 (SAPAP3) is a scaffold protein that is highly expressed in striatal excitatory synapses. While loss of SAPAP3 is known to cause obsessive-compulsive disorder-like behaviors in mice and reduce extracellular field potentials in the striatum, the mechanism by which SAPAP3 regulates excitatory neurotransmission is largely unknown. This study demonstrates that Sapap3 deletion reduces AMPAR-mediated synaptic transmission in striatal medium spiny neurons (MSNs) through postsynaptic endocytosis of AMPARs. Striatal MSNs in Sapap3 KO mice have fewer synapses with AMPAR activity and a higher proportion of silent synapses. We further find that increased metabotropic glutamate receptor 5 (mGluR5) activity in Sapap3 K0 mice underlies the decrease in AMPAR synaptic transmission and excessive synapse silencing. These findings suggest a model whereby the normal role of SAPAP3 is to inhibit mGluR5-driven endocytosis of AMPARs. The results of this study provide the first evidence for the mechanism by which the SAPAP family of scaffold proteins regulates AMPAR synaptic activity.

\section{Introduction}

Excitatory synaptic transmission mediated by AMPA-type glutamate receptors (AMPARs) is fundamental to information processing in the brain. Scaffold proteins in the postsynaptic density (PSD) play a key organizational role in regulating the insertion and removal of AMPARs, thereby affecting the efficacy of synaptic transmission (Kim and Sheng, 2004). SAP90/PSD-95-associated proteins (SAPAPs, also referred to as guanylate kinase-associated proteins or GKAPs) are a family of PSD proteins that are unique to excitatory synapses (Kim et al., 1997; Takeuchi et al., 1997; Welch et al., 2004). SAPAPs can interact with many postsynaptic molecules-including Shank and PSD-95 (Kim and Sheng, 2004). The interaction of Shank and PSD-95 with SAPAPs suggests that SAPAPs may influence the activity of ionotropic and/or metabotropic glutamate receptors. Of the four family members, SAPAP3 (SAP90/PSD-95-associated protein 3) is the only one that is highly expressed in the striatum (Welch et al., 2007). In recent work, we found that genetic deletion of Sapap3 in mice reduced the field population spike response in striatum and that

\footnotetext{
Received May 19, 2011; revised Sept. 28, 2011; accepted Sept. 30, 2011.

Author contributions: Y.W., G.F., and N.C. designed research; Y.W. performed research; Y.W. and N.C. analyzed data; Y.W., G.F., and N.C. wrote the paper.

We acknowledge members of the Calakos and Feng laboratories for stimulating discussions; Samantha Tracy, Zachary Caffall, Audrey Nelson, and Yuanji Pan for critical technical support; D. L. Armstrong, A. E. West, D. Stellwagen, and S. H. Soderling for comments on this manuscript; and the financial support of NARSAD, the Klingenstein Fund, the Tourette Syndrome Association, NINDS Grants NS064577, NS064577-S1 ARRA (American Recovery and Reinvestment Act) supplement, and NS054840 to N.C., and NIMH Grant MH081201, a Simon's Foundation Autism Research Initiative (SFARI) Grant and a Hartwell Individual Biomedical Research Award from The Hartwell Foundation to G.F.

Correspondence should be addressed to Nicole Calakos, Box 2900, Duke University Medical Center, Durham, NC 27710. E-mail: nicole.calakos@duke.edu.

G. Feng's present address: Department of Brain and Cognitive Sciences, McGovern Institute, MIT, Cambridge, MA 02139.

DOI:10.1523/JNEUROSCI.2533-11.2011

Copyright $\odot 2011$ the authors $\quad 0270-6474 / 11 / 3116685-07 \$ 15.00 / 0$
}

this defect could be acutely reversed by viral-mediated expression of SAPAP3 in striatum (Welch et al., 2007). However, the mechanism by which SAPAP3 regulates striatal excitatory neurotransmission is not understood. In addition, Sapap3 KO mice demonstrated pathological grooming and anxiety behaviors suggesting potential relevance to obsessive-compulsive disorder in humans (Welch et al., 2007). Thus, a better understanding of how SAPAP3 regulates striatal AMPAR-dependent neurotransmission may also help to elucidate potential mechanisms for neuropsychiatric disorders.

In this study, we examine excitatory synaptic transmission in striatal medium spiny neurons (MSNs) of Sapap3 KO mice. We demonstrate that loss of SAPAP3 reduces AMPAR-mediated synaptic transmission, and does so through postsynaptic endocytosis of AMPARs. Moreover, Sapap3 KO MSNs have fewer synapses with AMPAR activity and an increase in the proportion of silent synapses (i.e., those containing only NMDA-type glutamate receptors or NMDARs). Importantly, we find that these synaptic defects are not static, but can be acutely reversed by antagonism of metabotropic glutamate receptor 5 (mGluR5) activity. These findings define a role for SAPAP scaffold proteins in the dynamic regulation of AMPARs at synapses.

\section{Materials and Methods}

Brain slice preparation. Animal procedures were done according to protocol approved by the Institutional Animal Care and Use Committee of Duke University. Generation of Sapap3 KO, Drd1a-tdTomato transgenic, and Drd2-EGFP transgenic mice has been previously described (Gong et al., 2003; Welch et al., 2007; Shuen et al., 2008). Acute coronal brain slices (300 $\mu \mathrm{m}$ thickness) were obtained from postnatal day 21 (P21)-P25 Sapap3 wild-type (WT) and KO mice, both male and female, expressing Drd1a-tdTomato and/or Drd2-EGFP transgenes. The mice were anesthetized, transcardially perfused with ice-cold sucrose artificial CSF (ACSF) oxygenated with $95 \% \mathrm{O}_{2}$ and $5 \% \mathrm{CO}_{2}$, and then decapi- 
tated. Brains were removed and sectioned in oxygenated, ice-cold sucrose ACSF with a Vibratome 1500 (Vibratome). Sucrose ACSF contained (in mM) 194 sucrose, $30 \mathrm{NaCl}, 4.5 \mathrm{KCl}, 1.2 \mathrm{NaH}_{2} \mathrm{PO}_{4}, 0.2 \mathrm{CaCl}_{2}, 2$ $\mathrm{MgCl}_{2}, 26 \mathrm{NaHCO}_{3}$, and $10 \mathrm{D}-(+)$-glucose. Slices were maintained in standard ACSF saturated with $95 \% \mathrm{O}_{2}$ and $5 \% \mathrm{CO}_{2}$ at room temperature $\left(24-25^{\circ} \mathrm{C}\right)$ for at least $1 \mathrm{~h}$ before recording. Standard ACSF contained (in mм) $124 \mathrm{NaCl}, 2.5 \mathrm{KCl}, 1.2 \mathrm{NaH}_{2} \mathrm{PO}_{4}, 2 \mathrm{CaCl}_{2}, 1 \mathrm{MgCl}_{2}, 26 \mathrm{NaHCO}_{3}$, and $10 \mathrm{D}-(+)$-glucose.

Electrophysiology. Recordings were obtained at room temperature. $\mathrm{GABA}_{\mathrm{A}}$ receptors were blocked by $50 \mu \mathrm{M}$ picrotoxin (Sigma-Aldrich). Glycine $(1 \mu \mathrm{M})$ was present in NMDAR EPSC experiments. Fluorescence by transgene reporters was used to identify MSN types. Unless otherwise noted, all data are reported from tdTomato-positive, striatonigral MSNs. Recording pipette resistances were 3-4.5 $\mathrm{M} \Omega$, with internal solution containing the following (in $\mathrm{mm}$ ): 107 cesium methanesulfonate, 10 $\mathrm{CsCl}, 3.7 \mathrm{NaCl}, 5$ tetraethylammonium-Cl, 20 HEPES, 10 BAPTA-K $_{4}, 0.2$ EGTA, 5 lidocaine $N$-ethyl chloride, 4 ATP-Mg, 0.3 GTP-Na 3 , pH 7.27.3. Experiments were discarded if series resistance (typically $10-15 \mathrm{M} \Omega$ ) changed by $>20 \%$. Cell membrane potential was held at $-70 \mathrm{mV}$, unless specified otherwise, using an Axopatch 200B amplifier (Molecular Devices). Signals were low-pass filtered at $2 \mathrm{kHz}$ and sampled at $10-20 \mathrm{kHz}$ with a Digidata 1440A (Molecular Devices), and data were stored on a computer for subsequent off-line analysis.

To evoke EPSCs, $150 \mu$ s duration stimuli were delivered at $0.05 \mathrm{~Hz}$ through a bipolar electrode made of monopolar tungsten electrodes (FHC, Inc.). The stimulating electrode was placed in corpus callosum adjacent to dorsolateral striatum. Paired-pulse ratio refers to the ratio of the peak of the second EPSC to the peak of the first EPSC using a $50 \mathrm{~ms}$ interstimulus interval. AMPAR/NMDAR ratio is the ratio of the peak of the EPSC at $-70 \mathrm{mV}$ to the magnitude of the EPSC at $+40 \mathrm{mV}$ at $60 \mathrm{~ms}$ following stimulation. In MK-801 experiments, evoked NMDAR EPSCs were recorded in $10 \mu \mathrm{M}$ NBQX (Tocris Bioscience), $50 \mu \mathrm{M}$ picrotoxin, 1 $\mu \mathrm{M}$ glycine at a holding potential of $-40 \mathrm{mV}$. After NMDAR responses stabilized under $0.1 \mathrm{~Hz}$ stimulation, $40 \mu \mathrm{M}$ MK-801 (Tocris Bioscience) was bath applied and allowed to equilibrate without stimulation for 10 min. Thereafter, $0.1 \mathrm{~Hz}$ stimulation resumed and the decay constant for blockade of NMDAR EPSCs (number of trials to reach $36.8 \%$ of baseline response size) was estimated by a single exponential fit. In experiments using D15 and S15 peptides, the peptides were dissolved $(200 \mu \mathrm{M})$ in the internal solution. D15 peptide (PPPQVPSRPNRAPPG) constitutes a segment of the PRD domain of dynamin and inhibits clathrinmediated endocytosis (Lüscher et al., 1999). The corresponding scrambled peptide (S15) sequence was ANVRRGPPPPPQPSP. Inputoutput recordings were made $30 \mathrm{~min}$ after establishing whole-cell configuration. Time course recordings were performed as described by Lüscher et al. (1999) with $60 \mathrm{~s}$ stimulus intervals. EPSC responses were normalized to the amplitude of first response recorded $\sim 5 \mathrm{~min}$ after whole-cell configuration.

Miniature EPSCs were recorded in $1 \mu \mathrm{M}$ TTX (Tocris Bioscience) and analyzed using Mini Analysis Program (Synaptosoft). In AM251 (N(piperidin-1-yl)-5-(4-iodophenyl)-1-(2,4-dichlorophenyl)-4-methyl-1 $\mathrm{H}$ pyrazole-3-carboxamide) experiments, $0.05 \%$ bovine serum albumin (Sigma) was present in standard ACSF containing $3 \mu \mathrm{M}$ AM251 (Tocris Bioscience). Slices were preincubated with AM251 for at least $1 \mathrm{~h}$ before recording and continuously perfused with AM251 during recording.

In minimal stimulation experiments, evoked EPSCs were first obtained at $-60 \mathrm{mV}$ and stimulus intensity was reduced until response failures occurred $\sim 50 \%$ of trials. Sixty responses were evoked at frequency of $0.1 \mathrm{~Hz}$ at $-60 \mathrm{mV}$. Holding potential was then switched to $+50 \mathrm{mV}$ and sixty responses were obtained with identical stimulus intensity and frequency. Failure rates $(F)$ at -60 and $+50 \mathrm{mV}$ were measured. Percentage of silent synapses was calculated as $1-\ln \left(F_{-60 \mathrm{mV}}\right) /$ $\ln \left(F_{+50 \mathrm{mV}}\right)$ (Isaac et al., 1995; Liao et al., 1995).

In mGluR5 blockade experiments, brain slices were incubated in standard ACSF containing $40 \mu \mathrm{M}$ MPEP (Tocris Bioscience) or vehicle. Each coronal slice was hemisected and one half placed in each of the two solutions. Slices were incubated with drug for at least $2 \mathrm{~h}$ before recording. Recordings from each solution were interleaved on the same experimental day. CDPPB (10 $\mu \mathrm{M}$, Tocris Bioscience) experiments were done similarly except that $3 \mu \mathrm{M}$ AM251 was present in all conditions to prevent presynaptic effects from endocannabinoids.

Statistical analysis. Data are presented as mean \pm SEM. All error bars indicate SEM. Group results were compared by using $t$ test, ANOVA, or Mann-Whitney test. An asterisk in figures indicates a $p$-value of $<0.05$, the threshold used for statistical significance.

\section{Results}

\section{Striatal MSNs of Sapap3 KO mice have reduced} AMPAR-mediated synaptic transmission

Previously, we found that field population spike responses were reduced in the striatum of Sapap3 KO mice (Welch et al., 2007). To directly evaluate synaptic transmission, we performed wholecell recordings from dorsolateral striatal MSNs. According to their axonal projection patterns, striatal MSNs are classified into two types, striatonigral (or "D1" for expression of type 1 dopamine receptor) and striatopallidal (or "D2" for expression of type 2 dopamine receptor) MSNs (Gerfen, 1992). Since the two types of MSNs have different synaptic properties (Kreitzer and Malenka, 2008), we used transgenic mice expressing fluorescent marker proteins to distinguish striatopallidal and striatonigral MSNs (Shuen et al., 2008). In striatonigral MSNs identified by tdTomato fluorescence, we first measured the AMPAR/NMDAR ratio of evoked EPSCs to determine whether synaptic glutamate receptor activity was altered. We found that the AMPAR/ NMDAR ratio was significantly reduced in Sapap3 KO mice (WT, $1.53 \pm 0.07,29$ cells; KO, $1.20 \pm 0.05$, 26 cells; $p=0.001$, Mann-Whitney; Fig. $1 A$ ). To determine whether synaptic AMPAR activity was altered, we next measured the input-output relationship between stimulation intensity and the amplitude of evoked AMPAR EPSCs in striatonigral MSNs. The input-output curve of Sapap3 KO MSNs was markedly reduced compared with WT littermate controls (WT, 13 cells; KO, 12 cells; $p<0.001$, ANOVA; Fig. $1 B$ ), indicating that AMPAR-mediated synaptic transmission is reduced in striatonigral MSNs of Sapap3 KO mice.

Using EGFP fluorescence to identify striatopallidal MSNs, we investigated whether AMPAR synaptic transmission was similarly affected in this cell population. Like striatonigral MSNs, striatopallidal MSNs in Sapap3 KO mice had a reduced AMPAR/ NMDAR ratio (WT, $1.26 \pm 0.07,23$ cells; KO, $1.03 \pm 0.07,21$ cells; $p=0.013$, Mann-Whitney; Fig. $1 C$ ) and input-output curve of AMPAR EPSCs (WT, 11 cells; KO, 10 cells; $p<0.001$, ANOVA; Fig. 1D). Therefore, loss of SAPAP3 alters AMPAR synaptic transmission in a qualitatively similar manner in both striatonigral and striatopallidal MSNs. We further investigated the mechanistic basis for the AMPAR transmission reduction in a single MSN type-tdTomato-positive striatonigral MSNs.

To examine the activity of AMPARs at single synapses, miniature EPSCs (mEPSCs) were monitored. In Sapap3 KO MSNs, the frequency of mEPSC events was significantly reduced compared with WT controls (WT, $5.5 \pm 0.5 \mathrm{~Hz}, 8$ cells; KO, $3.5 \pm 0.6$ $\mathrm{Hz}, 8$ cells; $p=0.021, t$ test; Fig. $2 A, B)$. However, no differences in the amplitude of mEPSC events were observed (WT, $-14.7 \pm$ 1.2 pA, 8 cells; KO, $-14.2 \pm 0.8$ pA, 8 cells; $p=0.674$, MannWhitney; Fig. $2 A, C)$. These results demonstrate that there are fewer active AMPAR synapses, but no change in the size of the AMPAR response at synapses that are active. Such findings could be explained by a decrease in presynaptic release probability, a structural loss of synapses, or a loss of functional AMPARs from postsynaptic spines. 


\section{Striatonigral MSNs}

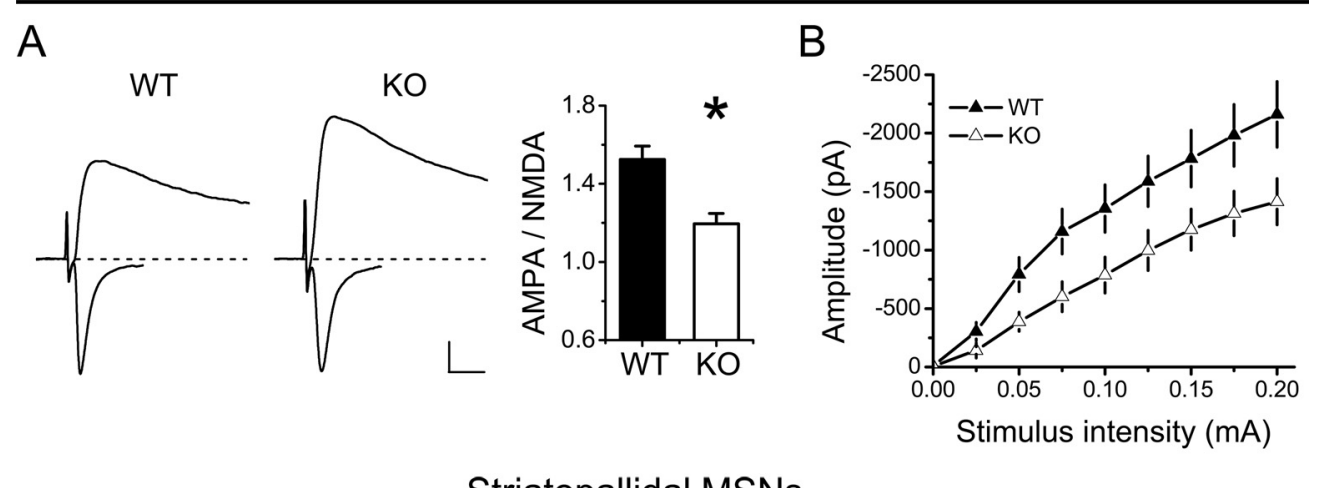

Striatopallidal MSNs
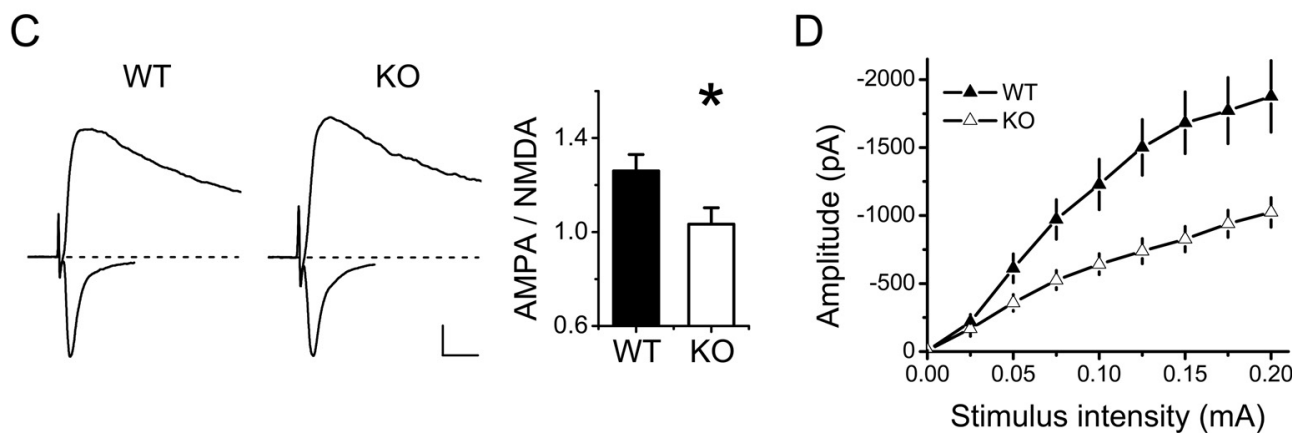

Figure 1. Sapap3 deletion reduces AMPAR synaptic transmission in striatonigral and striatopallidal MSNs. A, C, AMPAR/NMDAR ratio is decreased in MSNs of Sapap3 K0 mice. Representative traces are shown. Note: stimulus intensity was set to obtain an evoked EPSC of $\sim 400 \mathrm{pA}$ at $-70 \mathrm{mV}$ for both Sapap3WT and KO mice. Calibrations: $100 \mathrm{pA}, 20 \mathrm{~ms}$. B, D, Input- output curve of AMPAR EPSC amplitude is decreased in MSNs of Sapap3 K0 mice. * $p<0.05$.

\section{Presynaptic release probability is unchanged at striatal excitatory synapses in Sapap3 KO MSNs}

To examine whether presynaptic release probability is changed by Sapap3 deletion, we first measured the pairedpulse ratio of evoked EPSCs. Paired-pulse ratios were similar between WT and KO MSNs (WT, $0.98 \pm 0.03$, 29 cells; KO, $1.03 \pm 0.03,26$ cells; $p=0.183$, Mann-Whitney; Fig. $2 D)$. We next used the irreversible open-channel NMDAR antagonist, MK-801, to monitor presynaptic release probability (Hessler et al., 1993). Repeated activation of synapses in the presence of MK-801 results in a progressive decline of the evoked NMDAR EPSC. The rate of decline is directly proportional to the release probability. In the presence of MK-801 (40 $\mu \mathrm{M})$, NMDAR EPSCs declined similarly between WT and KO mice (decay constant: WT, $4.4 \pm 0.2$ trials, 10 cells; KO, $4.3 \pm 0.2$ trials, 11 cells; $p=0.833$, Mann-Whitney; Fig. 2 E). Thirdly, we tested whether the reduction in mEPSC frequency in Sapap3 KO MSNs was sensitive to type 1 cannabinoid receptor (CB1R) blockade because retrograde signaling by endocannabinoids in the striatum is a well described mechanism for inhibiting presynaptic release (Kano et al., 2009). In the presence of AM251 (3 $\mu \mathrm{M})$, mEPSC frequency was still reduced in $\mathrm{KO}$ MSNs compared with WT controls (WT, $6.5 \pm 1.0 \mathrm{~Hz}, 8$ cells; $\mathrm{KO}, 3.4 \pm 0.6 \mathrm{~Hz}, 8$ cells; $p=0.018, t$ test; Fig. $2 F$ ) and again, no differences in the amplitude of mEPSCs were observed between genotypes (WT, $-15.7 \pm 1.1 \mathrm{pA}, 8$ cells; KO, $-15.0 \pm$ 0.8 pA, 8 cells; $p=0.529$, Mann-Whitney; Fig. 2 F). Together these experiments demonstrate that presynaptic release probability is not altered in Sapap3 KO mice.

\section{Loss of SAPAP3 causes postsynaptic silencing of AMPAR synapses}

Thus far, our findings of an altered AMPAR/NMDAR ratio, a reduction in mEPSC frequency and normal presynaptic release probability indicate that a postsynaptic loss of synapses with functional AMPARs may underlie the synaptic defects of Sapap3 KO mice. In prior studies, we observed that MSNs of Sapap3 KO mice had the same numbers of spines as MSNs of WT mice (Welch et al., 2007). These observations indicate that functional AMPARs may be lost from postsynaptic spines without loss of the synapse itself. In this case, Sapap3 KO mice would be predicted to have a higher proportion of silent synapses (i.e., those having NMDAR activity, but not AMPAR activity) (Isaac et al., 1995; Liao et al., 1995). To directly test this possibility, we used the minimal stimulation method in which small numbers of silent and non-silent synapses are stimulated at -60 and $+50 \mathrm{mV}$ holding potentials (Fig. $2 G$ ). Because silent synapses only contribute to EPSCs at depolarized membrane potentials (conditions under which $\mathrm{Mg}^{2+}$ blockade of NMDARs is relieved), an increase in the proportion of silent synapses would be demonstrated by a greater increase in EPSC success rate from -60 to $+50 \mathrm{mV}$. As predicted, evoked EPSCs in Sapap3 KO MSNs had a greater increase in the success rate from -60 to $+50 \mathrm{mV}$ (WT: from $38.9 \pm 4.3 \%$ at -60 $\mathrm{mV}$ to $50.6 \pm 6.8 \%$ at $+50 \mathrm{mV}, 12$ cells; $\mathrm{KO}$ : from $40.4 \pm 3.2 \%$ at $-60 \mathrm{mV}$ to $62.0 \pm 4.2 \%$ at $+50 \mathrm{mV}, 14$ cells; $p=0.021$, MannWhitney; Fig. $2 \mathrm{H}$ ). Our results also show that the percentage of silent synapses is higher in Sapap3 KO MSNs (WT, 27.3 $\pm 6.3 \%$, 12 cells; KO, $45.6 \pm 4.2 \%$, 14 cells; $p=0.027$, Mann-Whitney; Fig. 2I). These findings demonstrate that in Sapap3 KO mice, the proportion of synapse types among striatal excitatory synapses is 

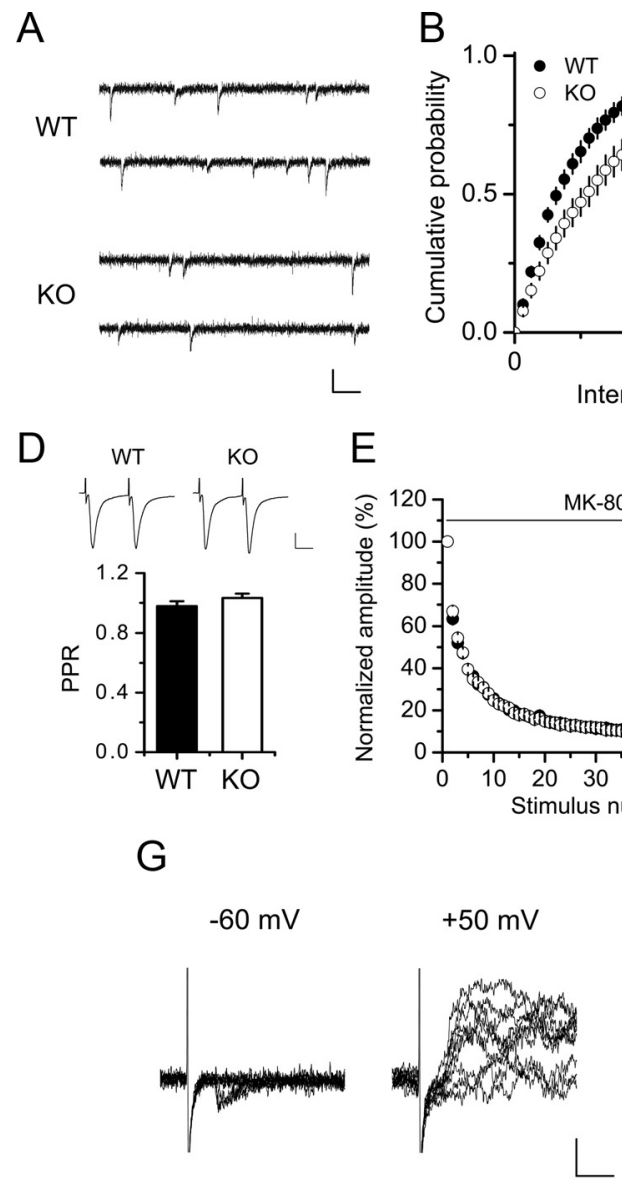

$\mathrm{E}$
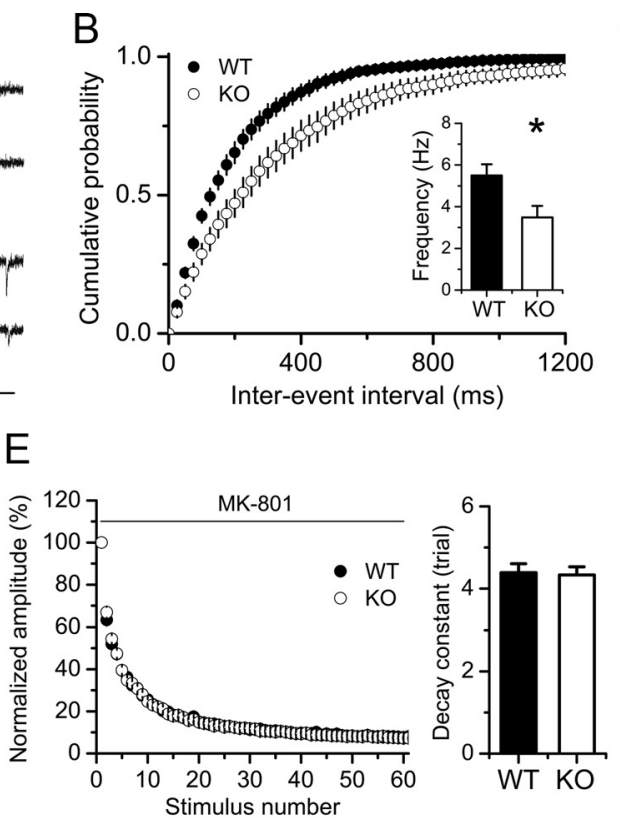

$\mathrm{H}$
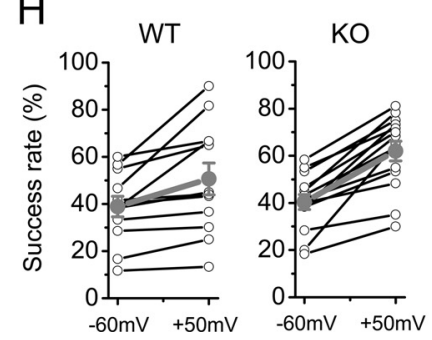

I

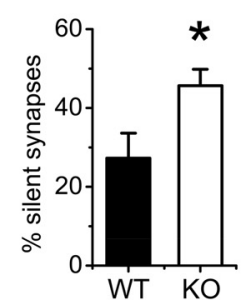

Figure 2. Striatonigral MSNs of Sapap3 $\mathrm{KO}$ mice have fewer miniature EPSCS, normal presynaptic release probability and an increase in silent synapses. $A$, Representative traces of mEPSC recordings. Calibrations: 20 pA, 100 ms. B, C, Frequency, but not amplitude, of mEPSCs is decreased in Sapap3 KO MSNs. D, Paired-pulse ratios (PPR) are normal in Sapap3 K0 MSNs. Calibrations: 100 pA, 20 ms. $\boldsymbol{E}$, Blockade rate of NMDAR EPSCS by MK-801 is similar between Sapap3 WT and KO MSNs. $\boldsymbol{F}$, Reduced mEPSC frequency observed in Sapap3 KO MSNs is insensitive to AM251. $\boldsymbol{G}$, Representative traces recorded from an MSN under minimal stimulation conditions at -60 and $+50 \mathrm{mV}$ holding potentials. Calibrations: $25 \mathrm{pA}, 10 \mathrm{~ms}$. $\boldsymbol{H}$, Success rates obtained at -60 and +50 $\mathrm{mV}$ in Sapap3 WT and KO MSNs. I, Percentage of silent synapses is increased in Sapap3 KO MSNs. ${ }^{*} p<0.05$.

altered-with fewer AMPAR-containing synapses and relatively more silent synapses.

\section{AMPAR endocytosis underlies the reduced excitatory synaptic transmission in Sapap3 KO MSNs}

To test whether AMPAR endocytosis contributes to the reduced striatal synaptic transmission in Sapap3 KO mice, we intracellularly loaded MSNs with D15 peptide. D15 peptide is a 15 aa segment of dynamin that inhibits AMPAR endocytosis by blocking the recruitment of dynamin to clathrin-coated pits (Lüscher et al., 1999). In Sapap3 KO MSNs, the D15 peptide significantly increased AMPAR EPSC amplitude compared with control peptide (S15) (input-output curves: S15, 6 cells; D15, 6 cells; $p<$ 0.001, ANOVA; Fig. 3A; time course recordings: S15, $95.1 \pm$ $4.0 \%, 5$ cells; D15, $164.7 \pm 18.5 \%, 5$ cells; $p=0.006, t$ test; Fig. 3B). Importantly, in Sapap3 WT MSNs, the D15 peptide had no effect on EPSC amplitude (S15, 6 cells; D15, 6 cells; $p=0.350$, ANOVA; Fig. 3C). Moreover, in the presence of D15 peptide, AMPAR transmission strength is no longer significantly different between WT and KO MSNs (WT, 6 cells; KO, 6 cells; $p=0.520$, ANOVA). As expected, paired-pulse ratios were not affected by these manipulations (KO: S15, $1.06 \pm 0.04,6$ cells; D15, $1.02 \pm$ $0.06,6$ cells; $p=0.337$, Mann-Whitney; WT: S15, $0.97 \pm 0.09,6$ cells; D15, $1.05 \pm 0.02,6$ cells; $p=0.522$, Mann-Whitney; Fig. $3 D$ ). These results show that endocytosis is uniquely activated in
Sapap3 KO MSNs and drives the reduction in AMPAR synaptic transmission that distinguishes KO from WT.

\section{Group 1 mGluR signaling contributes to the synaptic defects of Sapap $3 \mathrm{KO}$ mice}

Group 1 mGluR activation can cause AMPAR endocytosis and reduce excitatory synaptic transmission (Lüscher and Huber, 2010). We recently found that both the activity and dendritic surface levels of group $1 \mathrm{mGluRs}$ were increased in striatal MSNs of Sapap3 KO mice (Chen et al., 2011). To test the involvement of increased group 1 mGluR signaling, we asked whether blockade of mGluR5 [the predominant group 1 mGluR in MSNs (Testa et al., 1994)] normalized synaptic defects in Sapap3 KO mice. We found that treatment with $40 \mu \mathrm{M}$ MPEP increased the frequency of AMPAR mEPSCs in Sapap3 KO MSNs (frequency: vehicle, $3.7 \pm 0.7 \mathrm{~Hz}, 10$ cells; MPEP, $6.5 \pm 0.7 \mathrm{~Hz}, 10$ cells; $p=0.013, t$ test; amplitude: vehicle, $-17.2 \pm 0.8 \mathrm{pA}, 10$ cells; MPEP, $-17.6 \pm 0.5$ pA, 10 cells; $p=0.711$, Mann-Whitney; Fig. $4 A, B$ ). The increase in $\mathrm{mEPSC}$ frequency is unlikely to be explained by an increase in presynaptic release probability, because MPEP treatment did not significantly decrease paired-pulse ratio in $\mathrm{KO}$ MSNs (vehicle, $0.95 \pm 0.04,13$ cells; MPEP, $1.08 \pm 0.04,13$ cells; $p=0.980$, one-tailed Mann-Whitney; Fig. 4C). Instead, consistent with a postsynaptic mechanism, we found that MPEP treatment corrected the excessive postsynaptic silencing of AMPAR 
A
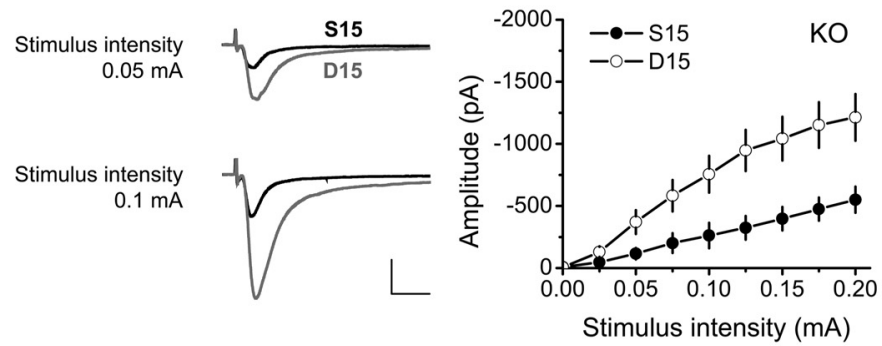

C
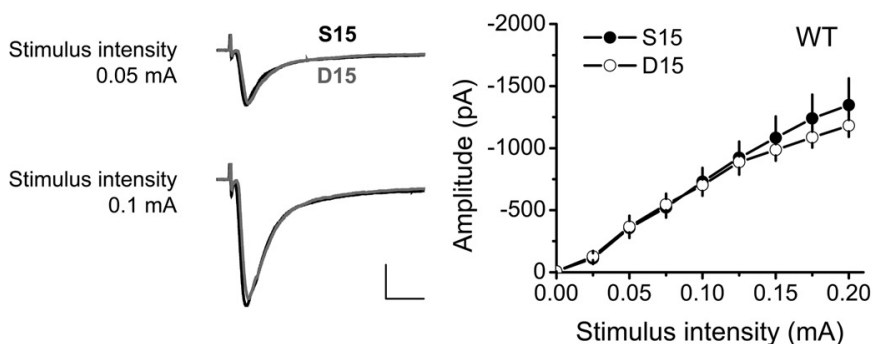

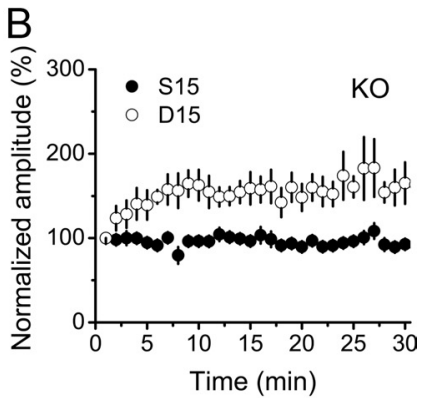

$\mathrm{D}$

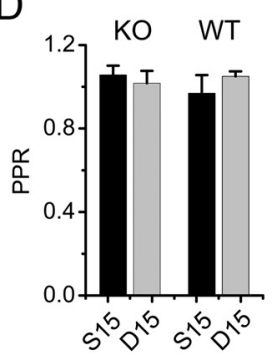

Figure 3. AMPAR endocytosis underlies the reduced AMPAR synaptic responses in Sapap3 KO striatonigral MSNs. A, In Sapap3 K0 MSNs, D15 peptide increases evoked AMPAR EPSC amplitude compared with control scrambled peptide (S15). Calibrations: 200 pA, 20 ms. B, Time course recordings of AMPAR EPSCs in KO MSNs. C, In Sapap 3 WT MSNs, D15 peptide has no significant effect on AMPAR EPSC amplitude. Calibrations: 200 pA, 20 ms. D, D15 and S15 peptides have no effect on PPR.

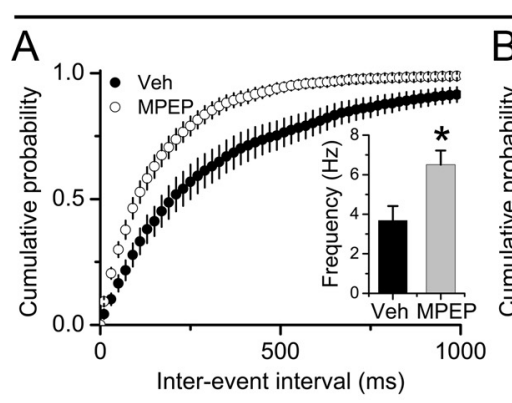

WT

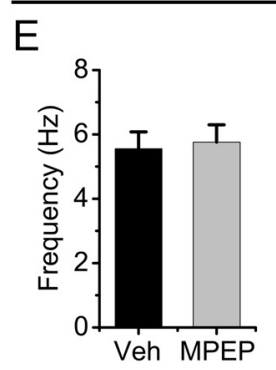

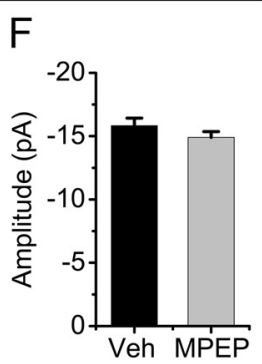

KO
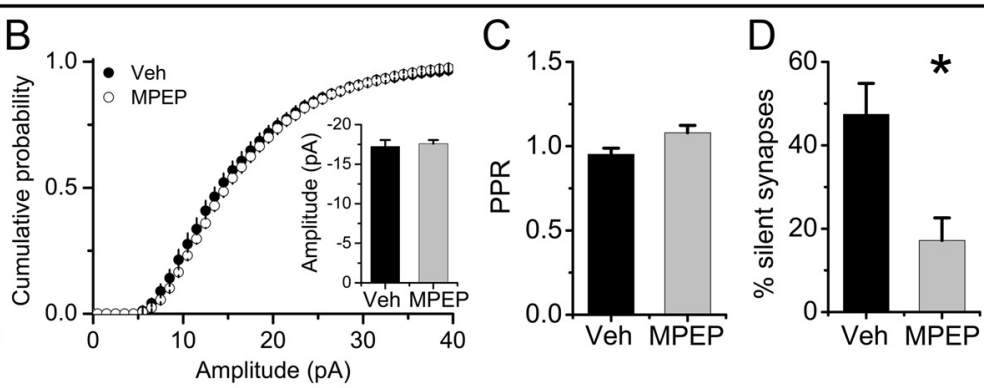

G

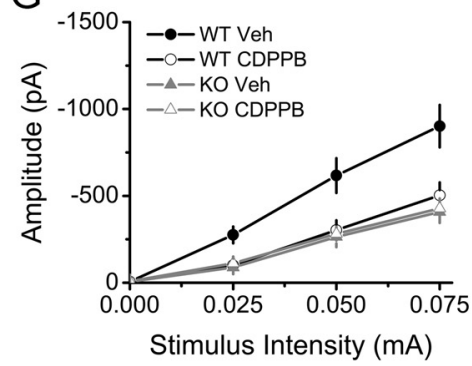

$\mathrm{H}$

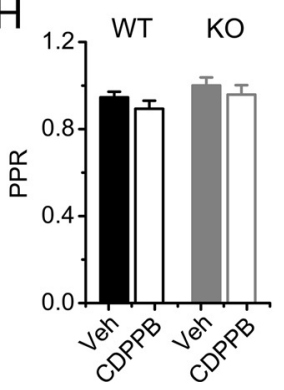

Figure 4. The mGluR5 antagonist, MPEP, reverses the altered AMPAR synaptic transmission in Sapap3 K0 striatonigral MSNs. $\boldsymbol{A}, \boldsymbol{B}$, In Sapap3 KO MSNs, MPEP treatment increases mEPSC frequency, but not amplitude. C, MPEP treatment does not change paired-pulse ratios (PPR) in Sapap3 KO MSNs. D, MPEP treatment decreases the percentage of silent synapses in Sapap3 KO MSNs. $E, F$, In Sapap 3 WT MSNs, MPEP treatment affects neither mEPSC frequency nor amplitude. G, Activating mGluR5 with CDPPB decreases AMPAR EPSC amplitude in WT MSNs to K0 levels, but has no effect on KO MSNs. $\boldsymbol{H}$, CDPPB treatment has no effect on PPR. Asterisk indicates $p<0.05$.

synapses found in Sapap3 KO MSNs. Compared with vehicle control, MPEP significantly decreased the percentage of silent synapses in Sapap3 KO MSNs (vehicle, $47.4 \pm 7.4 \%$, 8 cells; MPEP, $17.1 \pm 5.5 \%, 8$ cells; $p=0.006$, Mann-Whitney; Fig. $4 D$ ). As previously observed with D15 peptide treatment, the effects of MPEP on synaptic transmission were specific to Sapap $3 \mathrm{KO}$ mice. In WT MSNs, MPEP treatment had no discernable effects on mEPSC events (frequency: vehicle, $5.6 \pm 0.5 \mathrm{~Hz}, 10$ cells; MPEP,
$5.8 \pm 0.5 \mathrm{~Hz}, 10$ cells; $p=0.796, t$ test; amplitude: vehicle, $-15.8 \pm 0.6 \mathrm{pA}, 10$ cells; MPEP, $-14.9 \pm 0.5 \mathrm{pA}, 10$ cells; $p=$ 0.326 , Mann-Whitney; Fig. $4 E, F)$. In addition, genotype differences in mEPSC frequency were eliminated by MPEP treatment (WT, $5.8 \pm 0.5 \mathrm{~Hz}, 10$ cells; KO, $6.5 \pm 0.7 \mathrm{~Hz}, 10$ cells; $p=0.412$, $t$ test). Together this set of experiments provides strong evidence that, in Sapap3 KO mice, mGluR5 activity drives postsynaptic silencing of AMPAR synapses. 
To determine whether the mGluR5-dependent AMPAR endocytic pathway could also be activated in WT MSNs, we next augmented activity of mGluR5 receptors by incubation with an mGluR5-selective positive allosteric modulator, CDPPB. In striatal MSNs, group 1 mGluR activation is well known to stimulate endocannabinoid signaling and presynaptic depression (Kano et al., 2009). To prevent presynaptic effects, brain slices were coincubated with a CB1R antagonist (AM251). In the presence of CDPPB, we found that synaptic stimulation of Sapap 3 WT MSNs resulted in significant depression of AMPAR EPSC amplitude (vehicle, 9 cells; CDPPB, 10 cells; $p<0.001$, ANOVA; Fig. 4G). In KO MSNs, however, CDPPB incubation had no significant effect on AMPAR EPSCs (vehicle, 11 cells; CDPPB, 10 cells; $p=0.582$, ANOVA; Fig. 4G). Furthermore, as indicated by the paired-pulse ratio, no evidence for presynaptic effects was found between vehicle and CDPPB groups (WT: vehicle, $0.95 \pm 0.03,9$ cells; CDPPB, $0.89 \pm 0.04,10$ cells; $p=0.288$, Mann-Whitney; KO: vehicle, $1.00 \pm 0.04,11$ cells; CDPPB, $0.96 \pm 0.04,10$ cells; $p=$ 0.192, Mann-Whitney; Fig. $4 H$ ). These results demonstrate that mGluR5 activation in WT MSNs can postsynaptically decrease AMPAR responses and that this effect is occluded in Sapap3 KO MSNs.

\section{Discussion}

Regulation of AMPAR-mediated synaptic transmission is a central mechanism for controlling neuronal activity in the brain, with AMPAR synaptic strength being modulated both over developmental time and in response to activity-dependent experiences. The molecular events that regulate synaptic AMPARs are an area of intense investigation. By studying the effects of Sapap3 deletion on AMPAR synaptic transmission in MSNs, we implicate a new player in this process, the SAPAP family of scaffold proteins. Our findings support a role for SAPAP3 in inhibiting mGluR5 activity and the downstream triggering of AMPAR endocytosis.

Group 1 mGluR activation is a well known trigger for AMPAR endocytosis (Lüscher and Huber, 2010). However, group 1 mGluR-dependent AMPAR endocytosis has not been described in MSNs, nor did we find evidence in this study that this pathway was active under the basal conditions tested in WT MSNs. In WT MSNs, neither the blockade of clathrin-dependent endocytosis nor mGluR5 activity affected synaptic strength. These findings are consistent with prior observations, in which basal synaptic strength was unaffected by either the D15 peptide (Wang and Linden, 2000; Brebner et al., 2005; but see also Lüscher et al., 1999) or MPEP (Meredith et al., 2011). In marked contrast, in this study we found that when MSNs lack SAPAP3, blockade of either endocytosis or mGluR5 greatly increases AMPAR synaptic strength, returning it to WT levels. From these data, we conclude that SAPAP3 normally inhibits the activation of mGluR5dependent AMPAR endocytosis.

While we did not find evidence that mGluR5 activity normally contributes to AMPAR endocytosis in MSNs under our basal conditions of synaptic stimulation, we found that when mGluR5 activity was augmented by a positive allosteric modulator, AMPAR synaptic responses of WT MSNs were reduced to KO levels. This observation demonstrates that loss of SAPAP3 does not aberrantly create a unique signaling pathway in striatal MSNs, but rather augments activation of an existing pathway. In further support of the idea that mGluR5-dependent AMPAR endocytosis is increased in KO MSNs, we found that the CDPPB effect was occluded by the $\mathrm{KO}$ genotype. Moreover, we recently reported evidence that group 1 mGluR surface levels and activity were increased in Sapap3 KO MSNs (Chen et al., 2011). Together, these observations suggest that increased mGluR5 signaling is the primary insult in Sapap 3 KO MSNs and that AMPAR endocytosis is activated as a downstream consequence. Given the behavioral phenotype of Sapap3 KO mice, it is noteworthy that in Fmr1 KO mice, a model for fragile $\mathrm{X}$ syndrome which includes compulsive repetitive behaviors among other symptoms, increased mGluR5dependent AMPAR endocytosis is also observed, suggesting a potential shared mechanism (Nakamoto et al., 2007).

Without SAPAP3, striatal MSNs have fewer synapses with AMPAR activity and a consequent increase in the proportion of silent synapses. While much attention has been paid to silent synapses because of their developmental regulation and their role in synaptic plasticity, the ontogeny of silent synapses is not well understood at a molecular level (Hall and Ghosh, 2008). Current theories focus on a role for NMDARs in inhibiting synapse unsilencing (Kerchner and Nicoll, 2008). Our findings in Sapap3 KO mice bring forth a novel potential mechanism for generating silent synapses that involves active synapse silencing mediated by mGluR5-dependent AMPAR removal and regulated by SAPAP3. In future studies, it will be of interest to define whether and how SAPAP activity is dynamically regulated to alter synapse silencing. However, it is noteworthy that during development there is an inverse relationship between levels of mGluR5 and SAPAP. With age, levels of mGluR5 and silent synapses decline, while SAPAP levels increases (Petralia et al., 2005; Kerchner and Nicoll, 2008). These observations are at least consistent with the possibility that with developmental time, the presence of SAPAP downregulates mGluR5 and consequently decreases the abundance of silent synapses. Last, while an abundance of silent synapses might suggest a neurodevelopmental disorder because of its resemblance to an "immature" state, in this study, we find that this state is acutely reversible by mGluR 5 antagonism. The acute reversibility of the synaptic phenotype of Sapap3 KO mice highlights the importance of considering the contribution of an imbalance in biochemical signaling pathways to synaptic alterations found in neuropsychiatric disorders.

\section{References}

Brebner K, Wong TP, Liu L, Liu Y, Campsall P, Gray S, Phelps L, Phillips AG, Wang YT (2005) Nucleus accumbens long-term depression and the expression of behavioral sensitization. Science 310:1340-1343.

Chen M, Wan Y, Ade K, Ting J, Feng G, Calakos N (2011) Sapap3 deletion anomalously activates short-term endocannabinoid-mediated synaptic plasticity. J Neurosci 31:9563-9573.

Gerfen CR (1992) The neostriatal mosaic: multiple levels of compartmental organization in the basal ganglia. Annu Rev Neurosci 15:285-320.

Gong S, Zheng C, Doughty ML, Losos K, Didkovsky N, Schambra UB, Nowak NJ, Joyner A, Leblanc G, Hatten ME, Heintz N (2003) A gene expression atlas of the central nervous system based on bacterial artificial chromosomes. Nature 425:917-925.

Hall BJ, Ghosh A (2008) Regulation of AMPA receptor recruitment at developing synapses. Trends Neurosci 31:82-89.

Hessler NA, Shirke AM, Malinow R (1993) The probability of transmitter release at a mammalian central synapse. Nature 366:569-572.

Isaac JT, Nicoll RA, Malenka RC (1995) Evidence for silent synapses: implications for the expression of LTP. Neuron 15:427-434.

Kano M, Ohno-Shosaku T, Hashimotodani Y, Uchigashima M, Watanabe M (2009) Endocannabinoid-mediated control of synaptic transmission. Physiol Rev 89:309-380.

Kerchner GA, Nicoll RA (2008) Silent synapses and the emergence of a postsynaptic mechanism for LTP. Nat Rev Neurosci 9:813-825.

Kim E, Sheng M (2004) PDZ domain proteins of synapses. Nat Rev Neurosci 5:771-781.

Kim E, Naisbitt S, Hsueh YP, Rao A, Rothschild A, Craig AM, Sheng M (1997) GKAP, a novel synaptic protein that interacts with the guanylate 
kinase-like domain of the PSD-95/SAP90 family of channel clustering molecules. J Cell Biol 136:669-678.

Kreitzer AC, Malenka RC (2008) Striatal plasticity and basal ganglia circuit function. Neuron 60:543-554.

Liao D, Hessler NA, Malinow R (1995) Activation of postsynaptically silent synapses during pairing-induced LTP in CA1 region of hippocampal slice. Nature 375:400-404.

Lüscher C, Huber KM (2010) Group 1 mGluR-dependent synaptic longterm depression: mechanisms and implications for circuitry and disease. Neuron 65:445-459.

Lüscher C, Xia H, Beattie EC, Carroll RC, von Zastrow M, Malenka RC, Nicoll RA (1999) Role of AMPA receptor cycling in synaptic transmission and plasticity. Neuron 24:649-658.

Meredith RM, de Jong R, Mansvelder HD (2011) Functional rescue of excitatory synaptic transmission in the developing hippocampus in Fmr1-KO mouse. Neurobiol Dis 41:104-110.

Nakamoto M, Nalavadi V, Epstein MP, Narayanan U, Bassell GJ, Warren ST (2007) Fragile X mental retardation protein deficiency leads to excessive mGluR5-dependent internalization of AMPA receptors. Proc Natl Acad Sci U S A 104:15537-15542.

Petralia RS, Sans N, Wang YX, Wenthold RJ (2005) Ontogeny of postsyn- aptic density proteins at glutamatergic synapses. Mol Cell Neurosci 29:436-452.

Shuen JA, Chen M, Gloss B, Calakos N (2008) Drdla-tdTomato BAC transgenic mice for simultaneous visualization of medium spiny neurons in the direct and indirect pathways of the basal ganglia. J Neurosci 28:2681-2685.

Takeuchi M, Hata Y, Hirao K, Toyoda A, Irie M, Takai Y (1997) SAPAPs. A family of PSD-95/SAP90-associated proteins localized at postsynaptic density. J Biol Chem 272:11943-11951.

Testa CM, Standaert DG, Young AB, Penney JB Jr (1994) Metabotropic glutamate receptor mRNA expression in the basal ganglia of the rat. J Neurosci 14:3005-3018.

Wang YT, Linden DJ (2000) Expression of cerebellar long-term depression requires postsynaptic clathrin-mediated endocytosis. Neuron 25:635-647.

Welch JM, Wang D, Feng G (2004) Differential mRNA expression and protein localization of the SAP90/PSD-95-associated proteins (SAPAPs) in the nervous system of the mouse. J Comp Neurol 472:24-39.

Welch JM, Lu J, Rodriguiz RM, Trotta NC, Peca J, Ding JD, Feliciano C, Chen M, Adams JP, Luo J, Dudek SM, Weinberg RJ, Calakos N, Wetsel WC, Feng G (2007) Cortico-striatal synaptic defects and OCD-like behaviours in Sapap3-mutant mice. Nature 448:894-900. 